Running Head: Follower Needs and Leader Voice Enactment

When do Leaders Grant Voice?

How Leaders' Perceptions of Followers' Control and Belongingness Needs Affect The Enactment of Fair Procedures. 


\begin{abstract}
Theories that explain employees' positive emotional, cognitive and behavioral responses to fair procedures rely on control and relational processes. In the present study, we build on these models but reverse this perspective to examine when leaders provide voice opportunities in their interactions with employees. We argued that leaders may take care of employees' perceived individual control needs (which influence their own outcomes) by granting them with voice. However, this will be the case particularly when leader perceive that this employee also wants to belong to the organization, because this makes it more likely that employees will use their voice in a way that does not hurt the organization's interest. Support for this predicted interaction effect was found in a laboratory experiment and a multisource field study. This research is among the first to identify factors that influence whether leaders will be more likely to act fairly, thus integrating procedural justice processes in the leadership literature.
\end{abstract}

Keywords: voice, leadership, procedural fairness, need to belong, need for control 


\section{When do Leaders Grant Voice? How Leaders' Perceptions of Followers' Control and Belongingness Needs Affect The Enactment of Fair Procedures.}

One of the most robust findings in the organizational justice literature is that when employees are allowed to voice their opinion in decision making procedures, they perceive these procedures as more fair than when they are not allowed to do so (e.g. Folger, 1977; Van Prooijen et al, 2004). Such perceptions of procedural fairness (i.e. the extent to which authorities use fair procedures in allocating outcomes and in decision making processes, Leventhal, 1980; Thibaut and Walker, 1975) play a crucial role in influencing a variety of attitudinal and behavioral outcomes that are important to organizational functioning and employee wellbeing (see De Cremer and Tyler, 2005; Greenberg and Colquitt, 2005; Van den Bos and Lind, 2002 for overviews). For instance, granting voice to employees promotes employees' satisfaction and compliance with the leader, cooperative employee behaviors like organizational citizenship behavior, task performance, and ethical employee behavior (Brockner et al., 1998; De Cremer and Van Knippenberg, 2002, 2003; Folger and Cropanzano, 1998; Tyler et al., 1997; Weaver, 2004).

Given that the enactment of voice is such an important element of effective and ethical leadership, it is surprising how little we know about the conditions under which leaders actually enact procedural fairness (for a recent discussion on the importance of this issue, see Scott et al., 2009). In fact, studies that have focused on factors that influence leaders' procedural fairness enactment have only recently begun to surface. For instance, Scott et al. (2007) studied the effects of follower charisma and manager sentiments towards the follower as potential determinants of informational and interpersonal fairness. Brebels and colleagues (2011) identified leaders' moral identity as an important predictor of whether they grant voice to followers and are accurate when evaluating followers. Seppälä et al. (2012) found that when leaders perceive their followers as cooperative (e.g. helping), they are 
more likely to enact procedures in a fair manner and this effect is mediated by the leader's trust in the employee. Furthermore, Belliveau (2012) found that managers sometimes treat procedural fairness (i.e. post-decision voice) as a substitute for lower pay, but only in their interactions with female employees. This is presumably because many managers stereotypically believe that women are more communally oriented (i.e. focused on connection to others), and less agentic (i.e. focused on themselves and their own outcomes) than men. Finally, Blader and Chen (2012) argued that high status leaders focus on the needs of followers in order to maintain their status, whereas high power leaders are less focused on the needs of their followers. In support of this idea, they found a positive effect of high status and a negative effect of high power on the fairness behaviors of leaders.

Although these studies have all emphasized that fairness enactment deals with serving follower needs, and, hence that these needs might play a role in fairness enactment, only one very recent study directly examined the role of a follower need. That is, Cornelis et al. (2012) found a positive relation between follower belongingness need and leader fairness enactment. Interestingly, the justice literature has provided widespread evidence that procedural fairness enactment by leaders serves employees' need for control and their need to belong (Cropanzano et al., 2001; De Cremer and Tyler, 2005). In contrast to Cornelis et al (2012), we aim to develop and test a model that explains when organizational authorities will provide employees with voice opportunities as a function of perceptions of both follower control need and belongingness need. Because leadership deals with motivating employees to work in line with the interests of the organization (Hogan and Kaiser, 2005; Yukl and Van Fleet, 1992), leaders are likely to respond to the needs of employees (Organ, 1988; Zapata-Phelan et al., 2009). Building on these insights, we argue that leaders will take both of these needs into account when they consider giving employees voice. Specifically, we propose that these two needs will, in fact, interactively affect leaders' enactment of voice. 
The present study extends the procedural fairness literature in meaningful ways. First, the vast majority of research to date has studied the psychology of voice procedures by using it as an independent rather than dependent variable (Scott et al., 2009). Our research focuses on voice as a dependent variable and identifies determinants of this important leader behavior. Second, influential fairness research in the past decades has identified employees' need for control and their need to belong as two basic human needs served by leaders' fairness enactment, and thus as explanatory mechanisms of the positive effects of such leader behavior (e.g. see Cropanzano et al., 2001). We reverse the approach typically used in voice research by examining by examining how leaders' perceptions of these employee needs interactively affect whether leaders provide voice opportunities to their followers. Thus, in contrast to previous research we aim to show that granting voice not only has an important influence on employees, but is also shaped by the needs of employees. In doing so, we integrate the literature on fairness evaluations with the emerging literature on fairness enactment.

\section{Why people value procedural fairness: control and belonging}

The topic of procedural fairness was put on the research agenda by Thibaut and Walker's (1975) publication of the control model of justice. The central premise of this model is that people value fair procedures (i.e. voice) in their relationships with authorities because it gives them the feeling that these authorities take their interests into account, which maximizes the probability of obtaining fair or favorable outcomes in decision making processes (Greenberg and Folger, 1983; Tyler, 1987). The control (or instrumental; Tyler, 1987) model of justice has received strong support in the literature: when people receive voice it makes them feel that their views are taken into consideration by decision makers and, consequently that they can influence outcomes more than when not given voice (Barry and Shapiro, 2000; Greenberg, 2000). Other research reveals that people react to the fairness of 
decision making procedures particularly when they feel that they lack control (Van den Bos, 2001, Study 2) or when they actually do lack control in the decisions of authorities (Korsgaard et al., 1995). Thus, the control model of justice indicates that people find fair procedures such as voice important, because it serves their need for control (Cropanzano et al., 2001).

Yet, other research argued that a different need might explain people's reactions to the fairness of decision making procedures. For instance, Lind and colleagues (1990) showed that people also react positively to having voice after the decision has been made, making it impossible that their input will affect the actual outcome received. Studies like these have paved the way for relational models of justice such as the group-value model and the relational model of authority (Lind and Tyler, 1988; Tyler and Lind, 1992). These models build on the influential finding that people have a strong need to belong to social collectives (Baumeister and Leary, 1995). In support of these models, a wealth of research indicates that people value fair procedures such as voice, because they communicate a symbolic message of acceptance and standing in the group or organization (Tyler and Blader, 2000; Tyler and Lind, 1992). Furthermore, several studies show that particularly individuals with a strong need to belong are affected by the fairness of procedures and process information about procedures more carefully (De Cremer and Blader, 2006; see also De Cremer and Tyler, 2005; Van Prooijen et al., 2004).

Thus, whereas the control (or instrumental) model of justice argues that people value fair procedures (e.g. voice) because it serves their control need, relational (or noninstrumental) models of justice argue that people value fairness because it serves their need to belong (Cropanzano et al., 2001). Although these explanations have often been treated separately, more recently it has been argued that the models are actually intertwined (Shapiro and Brett, 2005). Indeed, a vast amount of work shows that fairness evaluations are driven 
by both instrumental and non-instrumental judgments (Lind and Tyler, 1988, pp. 240-241) and that both control needs and belongingness needs are important in followers' evaluation of the procedural fairness of authorities (e.g. Cropanzano et al., 2001; Mayer et al., 2008). Moreover, the higher these two needs are, the more strongly followers will value and comply with fair procedures such as voice (e.g. De Cremer and Blader, 2006; Van den Bos, 2001). But do leaders take these needs into account when enacting fair procedures?

\section{The present study: an actor perspective on fairness enactment}

Arguably the most important function of leadership is to direct followers towards the goals of the organization (e.g. Hogan and Kaiser, 2005; Yukl and Van Fleet, 1992). However, to motivate followers to work towards collective goals, leaders also need to ensure that employees' needs are satisfied at a certain level (cf. Mayer et al., 2008; Organ, 1988; ZapataPhelan et al., 2009). In support of this idea, a large number of studies show that leaders who pay attention to the needs of their employees are more effective in stimulating these followers' in- and extra-role performance (e.g. Dvir et al., 2002; Wang et al., 2005). This suggests that leaders should be motivated to pay attention to the needs of their followers in order to stimulate followers to focus on the collective welfare.

At the same time, organizations and leaders have been found to be somewhat reluctant in providing followers with voice (Brockner, 2006; Greenberg, 2009). One reason for this is that doing so might make organizations vulnerable as they concede a certain level of control to their followers (Brockner, 2006; Donaldson, 1990). This might especially be the case when it is uncertain whether followers share the same goals as the leader and organization (Vroom and Jago, 1974; Yukl and Fu, 1999). Likewise, the needs of followers may not always be in line with the interests of the organization (Argyris, 1964). Followers with a strong need for control might want to influence outcomes that serve their own interests rather than those of the organization (Simons, 1995). Therefore, it stand to reason that leaders might not always 
grant more voice to followers with a perceived high control need, especially when they sense that those followers might only desire influence over their own outcomes.

Following the reasoning above, it seems important for leaders not to focus on the control needs of their followers only, but to align these needs explicitly with the organization's interests. More specifically, we argue that leaders are willing to take into account the control needs of their followers (i.e. by giving them voice when making decisions that concern these followers), but particularly when they believe that followers also strongly value being a part of, and working for the organization.

One relevant variable that influences leader beliefs about employees' willingness to be part of the organization might be followers' need to belong. First of all, a perceived high need to belong signals that employees want to have long-term, positive and stable relationship with their organization (cf. Baumeister and Leary, 1995). Second, employees with a perceived high need to belong to the organization are more likely seen as motivated to exert effort on behalf of the organization than employees with a low need to belong (Meyer and Allen, 1991). Thus, a high need to belong signals that employees are not only motivated by self-interested concerns, but are also motivated to engage in behaviors that make them feel included in their organization. Therefore, we propose that leaders are more likely to grant voice when they perceive that a follower has a high rather than a low need for control (i.e. the desire to influence self-relevant decisions and outcomes). However, we argue that it is important for leaders to perceive that a follower is not only motivated by a need for control but also by a need to belong. Hence, we hypothesize that:

Leaders will grant more voice to a follower when they perceive this follower to have a high rather than a low need for control, but this effect of control need on granting voice will be found particularly when leaders believe that the follower also has a high need to belong. We tested this prediction regarding the interactive effect of followers' perceived 
control and belongingness need on leaders' voice enactment in two studies. Study 1 is a laboratory experiment in which all participants were assigned to the position of group leader who could choose how much voice to give to one of their followers. We orthogonally manipulated the strength of this follower's control and belongingness needs. In order to increase the external validity of our findings, Study 2 was a multisource field study that relied on employees and their leaders from a variety of different organizations as respondents.

\section{Study 1}

Method

Participants 98 business undergraduates ( 73 female and 25 male, $M_{\text {age }}=21.01$ years $S D=4.41)$ from a Dutch University, participated in this study in return for 7 Euros. They were randomly assigned to a 2 (follower control need: low vs. high) x 2 (follower belongingness need: low vs. high) design.

Procedure Upon arriving in the laboratory, participants learned that they would take part in a group study. Sitting in adjacent, soundproof cubicles, they worked on the study using a computer. All communication took place (in Dutch) via the computer, which participants believed to be linked to a central server. In the first part of the experiment, participants filled out several questionnaires. We supposedly used these questionnaires in a later phase of the study to appoint participants to the leader position. Additionally, these questionnaires were used to promote the credibility of the follower control and belongingness needs manipulations.

Next, the participants learned that they would work on an in basket test, which is a managerial simulation task that is often used in selection procedures to assess specific competencies of job applicants. The in basket test is also used to provide a realistic work setting to laboratory experiments (Treviño, 1992). We used a version of the test that involves a group situation in which there is one leader (i.e. manager) and four employees. Participants 
believed that these roles would be appointed based upon their answers to some of the questionnaires that they filled out at the start of the experiment that measured leadership skills. This procedure is often used in studies to appoint participants as leaders in a legitimate manner (e.g. Hoogervorst et al., 2010; Stouten and Tripp, 2009). In reality, each participant was appointed to the leader position and believed that (s)he supervised four employees.

After being explained in detail what the in basket task entailed and what the responsibilities of their personal role as a leader would be (e.g. prioritizing emails and memos, distributing tasks and supervising employees, making decisions), we introduced the manipulations of employees' control and belongingness needs. Supposedly to get to know their employees better, participants received the results of analyses of their employees' answers on the questionnaires they had filled out at the beginning of the experiment. They would receive the results for group member A first, then for group member B, and so on. In the high control need conditions, participants read the following information about group member A:

Group member A is someone who lies awake at night when important decisions have to be made in his environment. He is someone who needs to feel part of the decision making process so that he can influence the outcomes

In the low control need conditions, participants read:

Group member A is someone who does not lie awake at night when important decisions have to be made in his environment. He is someone who has a low need to feel part of the decision making process and influence the outcomes

Subsequently, participants received information about the belongingness needs of the employee. In the high belongingness need conditions, the participants read:

The scores also show that Group member A needs to feel at home in his environment. Feeling like an included and valued member is of great importance to him. 
In the low belongingness need conditions, the participants read:

The scores also show that Group member A does not need to feel at home in his environment. Feeling like an included and valued member is not important to him.

Upon reading this information, participants learned that, as part of the task, they would have to make important decisions that could concern this particular group member A. We then employed our voice enactment measure. This measure was originally introduced by Brebels et al (2011) to measure accuracy in decision-making processes. We made slight adjustments in order to measure voice in a similar manner, providing us with an opportunity to measure the amount of voice granted by the leader at the behavioral level while avoiding the risk of demand characteristics. Specifically, participants read:

As the leader, you will have to decide on how you will distribute tasks among your followers and how you will evaluate your followers. To make these important decisions, you will have to go through 10 individual procedures (i.e. steps). For instance, these procedures include distributing tasks to individual followers, setting individual targets as well as setting targets for the team, setting evaluation criteria, and designing a reward/punishment system. Please indicate in how many of these ten procedures you want to grant voice to Group member A.

Finally, we assessed our manipulation checks on a seven-point Likert-scale $(1=$ Strongly disagree; 7 = Strongly agree). To assess whether our manipulation of follower control need was successful, we asked participants to respond to two items ( $\alpha=.97)$. Specifically, participants rated the extent to which they believed that their group member A needs to feel that he can influence "decisions" and "outcomes". Likewise, two items $(\alpha=$ 0.97) were included to assess whether we manipulated follower belongingness need successfully. Participants rated the extent to which they believed that group member A likes to feel "accepted" and "valued" in his environment. 
Note that while answering the dependent measures about Group Member A, the participants believed they would also receive information and had to answer questions about the other three group members. We did not provide explicit information about the gender of the four group members, although participants could infer that Group Member A was male ${ }^{1}$. After answering the questions about Group Member A, the experiment was terminated and participants were thanked, debriefed and paid.

Results

Manipulation checks A 2 (control need) x 2 (belongingness need) ANOVA revealed only a main effect of follower control need $F(1,94)=393.26, p<0.001, d=4.04$, on the control need scale. Participants in the high follower control need condition $(M=6.02, S D=$ 1.03) perceived a higher follower control need than those in the low follower control need condition $(M=2.00, S D=.96)$. The main effect of follower belongingness need $F(1,94)<1$, $n s, d=0.0$, and the interaction effect, $F(1,94)<1, n s$., were not significant

A 2 (control need) x 2 (belongingness need) ANOVA revealed only a main effect of follower belongingness need $F(1,94)=310.86, p<0.001, d=3.55$ on the belongingness need scale, showing that participants in the high follower belongingness need condition $(M=$ $6.42, S D=.66)$ perceived a higher follower belongingness need than those in the low follower belongingness need condition $(M=2.49, S D=1.42)$. The main effect of follower control need $F(1,94)=1.99, p=0.16, d=0.14$, and the interaction effect, $F(1,94)<1, n s ., d$ $=0.0$, were not significant.

These manipulation checks show that we successfully and independently induced our follower control and belongingness needs manipulations.

INSERT TABLE 1 ABOUT HERE 
Voice We conducted a 2 x 2 ANOVA on leader's decision of how many times they granted voice to the follower (out of 10 decisions) revealing a significant main effect of follower control need $F(1,94)=6.06, p<0.05, d=0.48$. This main effect was qualified by a significant interaction effect, $F(1,94)=6.05, p<0.05$ (see Table 1, and Figure 1). Simple effects tests revealed a significant main effect of follower control need when the follower had a high belongingness need $F(1,94)=12.11, p<0.01, d=1.09$, but not when this need was low $F(1,94)<1, n s, d=0.0$. Put differently, leaders provided more voice opportunities to followers with a high control need, but only to followers who also have a high need to belong.

\section{INSERT FIGURE 1 ABOUT HERE}

\section{Study 2}

Having causal data is important for the internal validity of our findings, but we also need to be able to demonstrate whether our findings can be generalized to organizational leadership. Therefore, we conducted a second study to test our predictions in actual work environments. To reduce concerns about socially desirable or self-serving biases associated with self-report measures (e.g. Donaldson and Grant-Vallone, 2002), we employed a multisource design in which leaders rated the control and belongingness needs of one of their employees. In turn, these employees rated the amount of voice they received from their leader.

Another concern might be that we manipulated follower's need to belong rather generally in Study 1, whereas in our theoretical argument we focus on need to belong to the 
organization specifically. We addressed this issue by measuring followers' need to belong to the their organization in Study 2.

\section{Method}

Sample and Procedure A random sample of 412 members of a Dutch research panel consisting of employees from a variety of different organizations were invited to fill out the questionnaire on a web page. For their participation, they received credit points that would allow them to receive certain gifts (i.e. movie tickets). A total number of 312 employees responded by filling out the questionnaire (a response rate of $75.7 \%$ ). These employees were requested to ask their direct supervisor to also participate in the study. Participants did so by sending a questionnaire link to their supervisor. Both the employee and supervisor surveys were administered online and we gave each respondent a unique identification number to ensure anonymity and to make sure we could match the employee and supervisor data.

We took a number of steps to ensure that the surveys were completed by the correct sources. First, in introducing the study, we emphasized the importance of integrity in the scientific process and that it was essential for them and their supervisor to fill out the correct surveys. Second, when respondents submitted their on-line surveys, time stamps and IP addresses were recorded to ensure that the employee and supervisor surveys were submitted at different times and with different IP addresses. We found no irregularities in the responses.

A total of 312 employees and 108 supervisors participated in the study. We included only the data of focal employees who had complete and matching supervisor data, resulting in 93 focal employee-supervisor dyads. The employees were on average 43.88 years old ( $S D$ $=9.78)$ and $36.6 \%$ were female. They worked on average for 10.9 years $(S D=10.27)$ in their organization and worked an average 6.1 years $(S D=6.51)$ in their current job. The employees with a matched supervisor did not differ from employees without a matched supervisor in 
terms of mean scores on the study variables (i.e. the demographic variables and rating of their supervisor's voice), or in terms of correlations between the study variables.

The supervisors were on average 46.1 years old $(S D=8.99)$ and $33.0 \%$ were female. They worked an average of 12.9 years $(S D=9.55)$ in their organizations and worked an average 6.1 years $(S D=5.51)$ in their current job.

\section{Measures}

Our instruments were presented in Dutch. All responses were given on 5-point scales $(1$ = strongly disagree $; 5$ = strongly agree $)$.

Perceived follower control need Employees' need for control as perceived by the supervisor $^{2}$ was measured using the following three-item scale $(\alpha=0.91)$ based on Burger and Cooper (1979) and Skinner (1996): "This employee has the need to influence important decisions in the organization", "This employee has the need to exercise some level of control when decisions are made in the organization" and "This employee finds it annoying when you have not taken into account his/her interest in making important decisions”.

Perceived follower belongingness need Employees' need to belong as perceived by the supervisor was assessed with a 3 item scale $(\alpha=0.92)$ based on the work of Baumeister and Leary (1995) and included "This employee has a high need to feel at home in the organization", "This employee has a high need to feel valued in the organization", and "This employee has a strong need to feel connected to the organization."

Voice The extent to which leader granted voice was measured by a three-item combination $(\alpha=.83)$ based on Colquitt (2001) and taken from Blader and Tyler (2003). The items included "My supervisor listens to my opinion when making decisions", "My supervisor involves me in his / her decisions", "My supervisor takes my opinion into consideration when making decisions". 
Control Variables Demographic variables might affect our hypothesized relations. Therefore we included employee and supervisor age, sex, and job tenure as control variables in our analyses.

\section{Results and Discussion}

OLS regression was used to assess the main and interaction effects of perceived follower control and belongingness need on the leader's enactment of voice. The interaction term was based on the centred versions of the independent variables (Aiken and West, 1991). The results are reported in Table 2 and Table 3. The high correlation between follower control and belongingness need (see Table 2 ) suggests that collinearity problems may have inflated our coefficient estimates. Yet, the VIFs give us no reason to worry about collinearity: The VIFs for follower control need, follower belongingness need and the interaction effect were $1.56,1.87$ and 1.27 respectively, which is far below commonly accepted tresholds (Myers, 1990).

\section{INSERT TABLE 2 AND TABLE 3 ABOUT HERE}

The results presented in the third step of Table 3 reveal a significant interaction effect between perceived follower control and belongingness need, $\beta=0.23, p<0.05$. Figure 2 visually represents this effect. Simple slope analyses (Aiken and West, 1991) revealed that, as expected, follower control need was significantly positively related to the voice granted by the leader when the follower need to belong was high ( $1 S D$ above the mean; $\beta=0.23, p=$ 0.057). In contrast, when follower's need to belong was low (1 $S D$ below the mean) no relation between follower control need and supervisor granting voice was found $\beta=-0.04, p$ $=0.78$ ). These results support our hypothesis and, as shown in Figure 2, reveal that the effect of control need becomes greater at higher levels of belongingness need. We also tested our 
hypotheses without the demographic background variables as control variables in the analyses. These analyses revealed similar, but slightly stronger results than the analyses with the control variables included, presumably because adding non-significant predictors decreases the overall power of the test.

\section{INSERT FIGURE 2 ABOUT HERE}

\section{General discussion}

Past research has illustrated convincingly that providing voice opportunities to employees can be an important ethical leadership tool. Indeed, voice effectively and positively influences employees (De Cremer and Van Knippenberg, 2002, 2003) and contributes to an ethical work climate (e.g. Brown et al., 2005; Weaver, 2004). Moreover, when they provide voice to employees, it becomes less likely that leaders themselves will abuse their power for self-interested motives (cf. De Hoogh and Den Hartogh, 2008). Yet, surprisingly little research has focused on the question when leaders actually involve followers in their decision making procedures (Scott et al., 2009).

In the present research we made the assumption that leaders need to be able to satisfy followers' needs, but this cannot happen to the detriment of the leader's primary task, that is, to foster the pursuit of the organizational interest. For that reason we argued that leaders may serve followers' control needs (which influence their own outcomes) by means of granting voice, but particularly so if they perceive that this follower also wants to belong to the organization. Across two studies (one experimental lab study and one multisource field study), we found support for this prediction: leaders granted more voice when interacting with a follower with a perceived high rather than a low control need, but this was particularly the case when the follower also had a perceived high need to belong to the organization. 


\section{Theoretical implications}

Our study is among the first to look at (procedural) fairness, and more specifically at voice as a dependent rather than an independent or explanatory variable. Although procedural fairness is commonly enacted by leaders (De Cremer and Tyler, 2010), and both leadership and procedural fairness deal with influencing and motivating followers (Chemers, 2001; Colquitt and Greenberg, 2003), the fairness and leadership literatures surprisingly are only rarely integrated (e.g. De Cremer and Tyler, 2010; Van Knippenberg et al., 2007). Indeed, fairness research has neglected leader-follower relations and has focused more on systemic or institutional forms of fairness enactment (Blader and Tyler, 2003; Van Knippenberg et al., 2007). In contrast, research on leadership effectiveness has often failed to include fairness in models of leadership (De Cremer and Tyler, 2010). The lack of studies that have taken an actor or leader perspective to studying fairness (Scott et al., 2009) illustrate well how these literatures are treated separately. With the present research, we believe to have provided a good example of how fairness and leadership research can be brought together by applying a more behavioral (i.e. leader) approach to studying fairness enactment.

In doing so, we build our study on prior research that has identified control and belongingness needs as two needs that are crucial in explaining why followers value fairness (e.g. Cropanzano et al., 2001). The present findings extend the importance of these needs in the procedural fairness process by showing that leader perceptions of these follower needs also affect the extent to which leaders grant voice to their followers. This dynamic approach to studying leader-follower relations fits nicely with recent calls for more research on how the influence between leaders and followers flows both ways rather than top-down only (Shamir, 2007). By showing that leaders consider follower needs when making decisions (especially when they are in line with organizational interests), our research extends knowledge about the dynamics and interdependence of leader-follower relations. 
Arguably, there are risks involved in giving employees a say in decision making processes. After all, employees might use their voice for self-interested goals which could put leaders and organizations in a vulnerable position. We argued that leaders will therefore consider the extent to which followers have a strong need to belong to the organization, in order to assess whether followers will use their voice to their own or, conversely the organization's benefit. This suggests that the leader's trust in the employee may mediate the interactive effect of followers' control and belongingness needs on leader's voice enactment. This would be in line with a study by Seppälä et al. (2012) who found that when leaders perceive their followers to be cooperative, they are more likely to enact procedures in a fair manner, and this effect is mediated by the leader's trust in the employee. We are unaware of studies that have linked perceptions of follower needs to leader's trust in followers, but it appears to fit well in theoretical trust models: When leaders believe that a follower not only desires control, but also wants to be an included member of the organization, this should make it more likely that leaders believe that the follower wants to benefit the organization, or in other words, is benevolent towards the organization. Given that beliefs about benevolence have been identified as important antecedents of trust (Mayer et al., 1995), trust could thus play an important role in the enactment of fair procedures.

\section{Practical implications}

Although research has repeatedly and robustly provided evidence for the importance of procedural fairness, it appears that leaders find it difficult or are reluctant to enact procedures fairly (Brockner, 2006; Folger and Skarlicki, 1998; Greenberg, 2009). Our findings show that when leaders believe that an employee wants to be part of decisionmaking processes and also wants be part of their organization this signals that this is someone who can be trusted to use his or her say to influence outcomes that do not harm the 
organization. Consequently, employees who want to belong to their organization (and value having control) are more likely to be involved in decision making processes by their leaders.

Our findings emphasize how organizations could benefit from a) promoting an environment in which employees are stimulated to speak up and discuss their needs with their superiors, and b) facilitating a workplace that employees want to be a part of. Indeed, when followers feel free to communicate their need to be involved in decision making procedures, this should make it more likely that leaders take this need into account. Moreover, employees who want to belong to their organization (and value having control) are more likely to be involved in decision making processes by their leaders. This could create a virtuous cycle in the organization: involving employees will have a positive influence on their perceptions, motivation and behaviors (De Cremer and Van Knippenberg, 2002, 2003; Folger and Cropanzano, 1998; Tyler et al., 1997). In turn, this creates a meaningful workplace that employees want to be a part of, making it more likely that leaders will continue to involve these employees and maintain a positive collaboration with followers.

\section{Limitations, strengths and suggestions for future research}

Of course each of our studies has its limitations and strengths. An important strength of our lab experiment is that it provides us with findings that are high in internal validity (e.g. De Cremer and Van Knippenberg, 2002). By giving participants (i.e. business undergraduate students) information about their follower's personality, we manipulated follower's control and belongingness needs rather explicitly in this study. The reason for doing this in such a straightforward and clear manner was to provide findings that were not confounded by individual difference of participants in how accurate they were in perceiving these needs. Still, our manipulation of follower control need ("someone who lies awake at night when important decisions will be made") might unintentionally have affected perceptions of follower anxiety in addition to level of control need. Taken together, this may raise some 
concerns on the generalizability of our findings to the actual leadership in organizations, in which follower needs might be less explicitly communicated.

We addressed the limitations of the lab study by conducting a second study in which we replicated our experimental findings in an actual work environment. Specifically, in Study 2 we employed a multisource design in which supervisors rated the perceived control and belongingness need of focal employees. In turn, these employees rated the amount of voice they received from their supervisor providing us with a behavioral measure of the voice enactment of leaders that is not based on self-reports. Yet, when considered in isolation, Study 2 also has clear limitations. Although it seems unlikely (i.e. employees had no incentive to do so), we cannot guarantee that employees did not also fill out the supervisor survey. Moreover, it would be difficult to draw clear conclusions from our field study without Study 1. For instance, an alternative explanation for the results of Study 2 is that leaders do not use their perceptions of their followers' control and belongingness needs to determine the amount of voice that they will give, but that they retrospectively adapt their perceptions of followers' control and belongingness needs to legitimize the level of voice that they gave to their followers. The experimental study is clearly important in ruling out this alternative explanation. Thus, although both of our studies are not without their shortcomings, when combined they provide us with robust evidence for the causal relation between follower control and belongingness need and the voice enactment of leaders.

Given that we examined leader perceptions of follower needs as predictors of the amount of voice that leaders provide to follower, it is possible that situational or individual difference variables that affect leaders' ability to accurately perceive these needs play a role in the processes that explain the enactment of voice. Indeed, some leaders may be more empathic to the needs of others (Judge et al., 2004) or better at taking the perspective and identifying the needs, thoughts and emotions of others (Galinsky et al., 2006). Furthermore, it 
has recently been suggested that status motivate leaders to focus more on the needs of employees, whereas power might make leaders focus less on the needs of others and more on their own goals (Blader and Chen, 2012). Future studies that examine the influence of leader perceptions of follower needs on fairness enactment could provide more insights in the role that variables such as perspective taking, power and status play in this process.

Naturally, there are still many unanswered questions regarding why and when leaders enact fair procedures (Scott et al., 2009). In the present research we examined whether leaders consider economical (i.e., control) and social (i.e., belonging) concerns of followers in their voice enactment. We did not focus on a third motive that explains why people care about fairness. That is, people also consider fairness as a moral value in itself, and people want to act as well as being treated accordingly (Folger, 1998). Therefore, it would be interesting to examine the underlying intentions of leaders' decision to enact voice or not. Do they do this because they believe it is the right thing to do? Or, do they have more selfinterested or instrumental reasons for enacting voice? One interesting avenue of research to test this idea would be to look at the importance of decision-making procedures in which leaders grant voice. If leaders are only willing to involve employees in decisions that are unimportant this would suggest that leaders grant voice instrumentally rather than out of moral concerns.

\section{Concluding remarks}

Former General Electrics CEO Jack Welch once said: 'The hardest part is to be fair.' (Tichy and Sherman, 1993; 148). This quote suggests that business leaders a) understand the importance of treating employees fairly but b) find it difficult to do so. Our findings suggest that leaders understand the importance of being fair to employees, and are less reluctant in enacting fairness when the needs of employees align with organizational interests. 


\section{References}

Aiken LS and West SG (1991) Multiple Regression: Testing and Interpreting Interactions. New York: Sage.

Argyris C (1964) Integrating The Individual and The Organization. New York: Wiley.

Barry B and Shapiro DL (2000) When will grievants choose voice? A test of situational, motivational, and attributional explanations. International Journal of Conflict Management 11(2): 106-134.

Baumeister RF and Leary MR (1995) The need to belong - Desire for interpersonal attachments as a fundamental human-motivation. Psychological Bulletin 117(3): 497529.

Belliveau MA (2012) How social accounts create vs. merely explain women's unfavorable pay outcomes. Organization Science 23(4): 1154-1174.

Blader SL and Chen Y-R (2012) Differentiating the effects of status and power: A justice perspective. Journal of Personality and Social Psychology 102(5): 994-1014.

Blader S and Tyler T (2003) A four-component model of procedural justice: Defining the meaning of a 'fair' process. Personality and Social Psychology Bulletin 29(6): 747-758.

Brebels L, De Cremer, D Van Dijke M and Van Hiel A (2011) Fairness as social responsibility: A moral self-regulation account of procedural justice enactment. British Journal of Management 22: 47-58.

Brockner, J, Heuer, L, Siegel, PA, Wiesenfeld, B, Martin, C, Grover, S, et al. (1998) The moderating effect of self-esteem in reaction to voice: Converging evidence from five studies. Journal of Personality and Social Psychology 75: 394-407.

Brockner, J (2006) Why it's so hard to be fair. Harvard Business Review 84(3): 122-129. 
Brown ME, Treviño LK and Harrison DA (2005) Ethical leadership: A social learning perspective for construct development and testing. Organizational Behavior and Human Decision Processes 97: 117-134.

Burger JM and Cooper HM (1979) The desirability of control. Motivation and Emotion 3: 381-393.

Chemers MM (2001) Leadership effectiveness: An integrative review. In: Hogg MA and Tindale RS (eds) Blackwell Handbook of Social Psychology: Group Processes. Oxford, UK: Blackwell, 376-399.

Colquitt JA (2001) On the dimensionality of organizational justice: A construct validation of a measure. Journal of Applied Psychology 86: 386-400.

Colquitt JA and Greenberg J (2003) Organizational justice: A fair assessment of the state of the literature. In: Greenberg J (ed.) Organizational Behavior: The State of The Science. Mahwah, NJ: Erlbaum, 165-210.

Cornelis I, Van Hiel A and De Cremer D (2012) The effect of followers' belongingness needs on leaders' procedural fairness enactment: Mediation through interpersonal and team attraction. Journal of Personnel Psychology 11: 31-39.

Cropanzano R, Byrne ZS, Bobocel DR and Rupp DE (2001) Moral virtues, fairness heuristics, social entities, and other denizens of organizational justice. Journal of Vocational Behavior 58: 164-209.

De Cremer D and Tyler TR (2005) Managing group behavior: The interplay between procedural justice, sense of self, and cooperation. In: Zanna M (ed.) Advances in Experimental Social Psychology. San Diego, CA: Academic Press, 151-218.

De Cremer D and Blader S (2006) Why do people care about procedural fairness? The importance of belongingness in responding and attending to procedures. European Journal of Social Psychology 36(2): 211-228. 
De Cremer D and Van Knippenberg D (2002) How do leaders promote cooperation? The effects of charisma and procedural fairness. Journal of Applied Psychology 87(5): 858866.

De Cremer D and Van Knippenberg D (2003). Cooperation with leaders in social dilemmas: On the effects of procedural fairness and outcome favorability in structural cooperation. Organizational Behavior and Human Decision Processes 91: 1-11.

De Cremer D and Tyler TR (2010) Being the leader and acting fairly: A contingency approach. In: De Cremer D van Dick, R and Murnighan JK (eds), Social Psychology and Organizations. Philadelphia: Taylor \& Francis, 39-66.

De Hoogh AHB and Den Hartog DN (2008) Ethical and despotic leadership, relationships with leader's social responsibility, top management team effectiveness and subordinates' optimism: A multi-method study. Leadership Quarterly 19: 297-311.

Donaldson L (1990) The ethereal hand: Organizational economics and management theory. Academy of Management Review 15: 369-381.

Donaldson SI and Grant-Vallone EJ (2002) Understanding self-report bias in organizational behaviour research. Journal of Business and Psychology 17(2): 245-260.

Dvir T, Eden D, Avolio BJ and Shamir B (2002) Impact of transformational leadership on follower development and performance: A field experiment. Academy of Management Journal 45: 735-744.

Folger R (1977) Distributive and procedural justice: Combined impact of "voice" and improvement on experienced inequity. Journal of Personality and Social Psychology 35: $108-119$.

Folger R and Cropanzano R (1998) Organizational Justice and Human Resource Management. Los Angeles: SAGE. 
Folger R and Skarlicki DP (1998) When tough times make tough bosses: managerial distancing as a function of layoff blame. Academy of Management Journal 41(1): 79-87.

Galinsky AD, Magee JC, Inesi ME and Gruenfeld, DH (2006) Power and perspectives not taken. Psychological Science, 17(12): 1068-1074.

Greenberg J (2000) Promote procedural justice to enhance acceptance of work outcomes. In: Locke EA (ed.) A Handbook of Principles of Organizational Behavior. Oxford, UK: Blackwell, 181-195

Greenberg J (2009) Everybody talks about organizational justice, but nobody does anything about it. Industrial and Organizational Psychology 2: 181-195.

Greenberg J and Folger R (1983) Procedural justice, participation, and the fair process effect in groups and organizations. In: Paulus P (Ed.), Basic Group Processes. New York: Springer-Verlag, 235-256.

Greenberg J and Colquitt JA (2005) Handbook of Organizational Justice. Mahwah, New Jersey: Lawrence Erlbaum Associates.

Hogan R and Kaiser RB (2005) What we know about leadership. Review of General Psychology 9: 169-180.

Hoogervorst N, De Cremer D and Van Dijke M (2010). Why leaders not always disapprove of unethical follower behavior: It depends on the leader's self-interest and accountability. Journal of Business Ethics 95(1): 29-41.

Judge TA, Piccolo RF and Ilies R (2004) The forgotten ones? The validity of consideration and initiating structure in leadership research. Journal of Applied Psychology 89: 36-51. Korsgaard MA, Schweiger DM and Sapienza HJ (1995) The role of procedural justice in building commitment, attachment, and trust in strategic decision-making teams. Academy of Management Journal 38: 60-84. 
Leventhal GS (1980) What should be done with equity theory? New approaches to the study of fairness in social relationships. In: Gergen K Greenberg M and Willis, R (eds) Social Exchange: Advances in Theory and Research. New York: Plenum Press, 27-55.

Lind EA, Kanfer R and Earley PC (1990) Voice, control, and procedural justice: Instrumental and noninstrumental concerns in fairness judgments. Journal of Personality and Social Psychology 59: 952-959.

Lind EA and Tyler TR (1988) The Social Psychology of Procedural Justice. New York: Plenum.

Mayer DM, Bardes M and Piccolo RF (2008) Do servant-leaders satisfy follower needs? An organizational justice perspective. European Journal of Work and Organizational Psychology 17: 180-197.

Meyer JP and Allen NJ (1991) A three-component conceptualization of organizational commitment. Human Resource Management Review 1(1): 61-89.

Myers R (1990) Classical and Modern Regression with Applications. Boston, MA: Duxbury. Organ DW (1988) Organizational Citizenship Behavior: The Good Soldier Syndrome. Lexington, MA: Lexington Books.

Scott BA, Colquitt JA and Paddock EL (2009) An actor-focused model of justice rule adherence and violation: The role of managerial motives and discretion. Journal of Applied Psychology 94: 756-769.

Scott BA, Colquitt JA and Zapata-Phelan CP (2007). Justice as a dependent variable: Subordinate charisma as a predictor of interpersonal and informational justice perceptions. Journal of Applied Psychology 92: 1597-1609.

Seppälä T, Lipponen, J, Pirttilä-Backman AM and Lipsanen J (2012) A trust-focused model of leaders' fairness enactment. Journal of Personnel Psychology 11: 20-30. 
Shamir B (2007) From passive recipients to active co-producers. Followers' roles in the leadership process. In: Shamir B Pillai R Bligh MC and Uhl-Bien M (eds) FollowerCentered Perspectives on Leadership: A Tribute to The Memory of James R. Meindl. Greenwich: Information Age Publishing, ix-xxxix.

Shapiro DL and Brett JM (2005) What is the role of control in organizational justice? In: Greenberg J and Colquitt J (eds) Handbook of Organizational Justice. Lawrence Erlbaum Associates, Mahwah, NJ, 155-77.

Simons R (1995) Control in the age of empowerment. Harvard Business Review 73(2): 8088.

Skinner EA (1996) A guide to constructs of control. Journal of Personality and Social Psychology 71: 549-570.

Stouten J and Tripp TM (2009) Claiming more than equality: Should leaders ask for forgiveness? The Leadership Quarterly 20: 287-298.

Thibaut J and Walker L (1975) Procedural Justice: A Psychological Analysis. Hillsdale, NJ: Erlbaum.

Tichy NM and Sherman S (1993) Control Your Own Destiny or Someone Else Will. New York: Simon \& Schuster.

Treviño LK (1992) Experimental approaches to studying ethical-unethical behavior in organizations. Business Ethics Quarterly 2(2): 121-136.

Tyler TR (1987) Conditions leading to value-expressive effects in judgments of procedural justice: A test of four models. Journal of Personality and Social Psychology 52: 333344.

Tyler TR and Blader SL (2000) Cooperation in Groups: Procedural Justice, Social Identity, and Behavioral Engagement. Philadelphia: Taylor \& Francis.

Tyler TR, Boeckman R, Smith HJ and Huo YJ (1997) Social Justice in a Diverse 
Society. Boulder, Colorado: Westview.

Tyler TR and Lind EA (1992) A relational model of authority in groups. In: Zanna M (ed.) Advances in Experimental Social Psychology. San Diego: Academic Press, 115-191. Van den Bos K (2001) Uncertainty management: The influence of uncertainty salience on reactions to perceived fairness. Journal of Personality and Social Psychology 80: 931941

Van den Bos K and Lind EA (2002) Uncertainty management by means of fairness judgments. In: M. Zanna (ed.) Advances in Experimental Social Psychology. San Diego, CA: Academic Press, 1-60.

Van Knippenberg D, De Cremer D and Van Knippenberg B (2007) Leadership and fairness: The state of the art. European Journal of Work and Organizational Psychology 16: 113140.

Van Prooijen J-W, Van den Bos K and Wilke HAM (2004) Group belongingness and procedural justice: Social inclusion and exclusion by peers affects the psychology of voice. Journal of Personality and Social Psychology 86: 66-79.

Vroom VH and Jago AG (1974) Decision making as a social process: Normative and descriptive models of leader behavior. Decision Sciences 5: 743-769.

Wang H, Law KS, Hackett RD, Wang D and Chen ZX (2005) Leader-member exchange as a mediator of the relationship between transformational leadership and followers' performance and organizational citizenship behavior. Academy of Management Journal 48: $420-432$.

Weaver GR (2004) Ethics and employees: Making the connection. Academy of Management Executive 18: 121-125.

Yukl G and Fu PP (1999) Determinats of delegation and consultation by managers. Journal of Organizational Behavior 20: 219-232. 
Yukl G and Van Fleet DD (1992) Theory and research on leadership in organizations. In: Dunnette MD and Hough L (eds) Handbook of Industrial and Organizational Psychology. Palo Alto, CA: Consulting Psychologists Press, 149-197.

Zapata-Phelan CP, Colquitt JA, Scott BA and Livingston B (2009) Procedural justice, interactional justice, and task performance: the mediating role of intrinsic motivation. Organizational Behavior and Human Decision Processes 108: 93-105. 


\section{Footnotes}

${ }^{1}$ To control for a potential effect of gender, we also conducted our ANOVAs with gender included. No main effects for gender or interaction effects were found. Moreover, the inclusion of gender in our analyses did not change the direction and significance of our results for control and belongingness needs.

${ }^{2}$ Given our focus on how follower needs affect leader behavior, it is important to examine leaders' perceptions of follower control and belongingness needs rather than actual follower needs. Of course, this raises the question how well leaders' perceptions of these needs correspond with the actual needs of their followers. Therefore, we also included a selfreport measure (using the same items) in Study 2 in which employees rated their own control and belongingness need. The self-reported need for control and need to belong was significantly correlated with how leaders rated these needs, $r=.52$ and $r=.43$ respectively. This suggests that leaders are actually quite accurate in how they perceive followers' control and belongingness needs. 
Table 1

Number of procedures in which the leader granted voice by follower control and belongingness need condition (Study 1)

Low belongingness need High belongingness need

\begin{tabular}{lcccc} 
& \multicolumn{2}{c}{ follower } & \multicolumn{2}{c}{ follower } \\
\cline { 2 - 5 } & $M$ & $S D$ & $M$ & $S D$ \\
\hline Low control need follower & 5.04 & 3.16 & 4.28 & 2.49 \\
High control need follower & 5.04 & 2.97 & 7.08 & 2.60 \\
\hline$N=98$ & & & & \\
& & &
\end{tabular}

$N=98$ 
Table 2

Means, standard deviations and intercorrelations of leader's voice enactment, follower's control and belongingness need and control variables (Study 2)

\begin{tabular}{|c|c|c|c|c|c|c|c|c|c|c|c|}
\hline & $M$ & $S D$ & 1 & 2 & 3 & 4 & 5 & 6 & 7 & 8 & 9 \\
\hline 1. Sex (employee) & - & .48 & - & & & & & & & & \\
\hline 2. Age (employee) & 43.88 & 9.78 & -.14 & - & & & & & & & \\
\hline 3. Tenure job in years (employee) & 6.09 & 6.51 & .04 & $.36^{* * *}$ & - & & & & & & \\
\hline 4. Sex (leader) & - & .47 & $.60 * * *$ & -.08 & -.13 & - & & & & & \\
\hline 5. Age (leader) & 46.10 & 8.99 & -.04 & $.55 * * *$ & $.30 * *$ & -.18 & - & & & & \\
\hline 6. Tenure job in years (leader) & 6.11 & 5.51 & .10 & .02 & $.55 * * *$ & .05 & $.22 *$ & - & & & \\
\hline 7. Leader's voice enactment & 3.58 & .71 & -.16 & .00 & -.15 & $-.214 *$ & .03 & -.19 & - & & \\
\hline 8. Follower's control need & 4.65 & 1.30 & -.07 & .02 & -.19 & -.08 & .15 & -.17 & $.32 * *$ & - & \\
\hline 9. Follower's belongingness need & 5.23 & .86 & .08 & .20 & .06 & .08 & .19 & -.11 & $.28 * *$ & $.60 * * *$ & - \\
\hline
\end{tabular}

$N=93, *<.05, * * p<.01, * * * p<.001$. 
Table 3

Results of hierarchical regression analysis for voice enactment of the leader in Study 2

\begin{tabular}{|c|c|c|c|}
\hline Variables & Step 1 & Step 2 & Step 3 \\
\hline Sex (employee) & -.02 & -.03 & -.00 \\
\hline Age (employee) & .07 & .05 & .07 \\
\hline Job tenure (employee) & -.21 & -.19 & -.24 \\
\hline Sex (supervisor) & -.24 & -.24 & $-.27 *$ \\
\hline Age (supervisor) & .01 & -.06 & -.07 \\
\hline Job tenure (supervisor) & -.08 & -.03 & -.01 \\
\hline Perceived employee control need (CN) & & .12 & .09 \\
\hline Perceived employee belongingness & & .21 & $.34 *$ \\
\hline \multicolumn{4}{|l|}{ need $(\mathrm{BN})$} \\
\hline $\mathrm{CN} \times \mathrm{BN}$ & & & $.23^{*}$ \\
\hline$R^{2}$ change & .11 & .08 & .04 \\
\hline$F_{\text {change }}$ & 1.70 & $4.12 *$ & $4.14^{*}$ \\
\hline$R_{\text {total }}^{2}$ & .11 & .19 & .23 \\
\hline$R^{2}$ adjusted & .05 & .11 & .15 \\
\hline$F_{\text {total }}$ & 1.70 & $2.40 *$ & $2.68 * *$ \\
\hline$d f$ & 6,83 & 8,81 & 9,80 \\
\hline
\end{tabular}

Note: For employee and supervisor sex, 0 denotes males, 1 denotes females. Table presents Beta coefficients.

$* p<.05, * * p<.01$ 
Figure captions

Figure 1. Interaction between perceived follower control and belongingness need on the number of voice opportunities provided by the leader (Study 1).

Figure 2. Interaction between perceived follower control and belongingness need on leader's voice enactment (Study 2). 
Figure 1

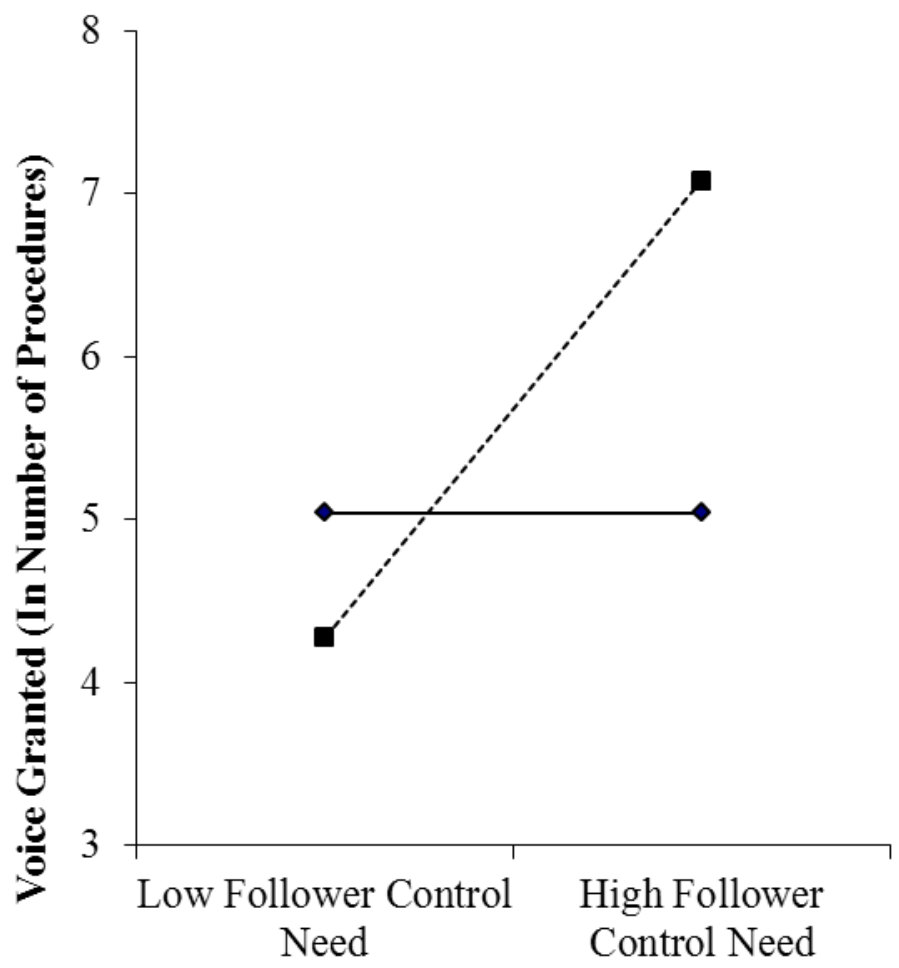

$\longrightarrow$ Low Follower Belongingness Need

------ High Follower

Belongingness Need 
Figure 2

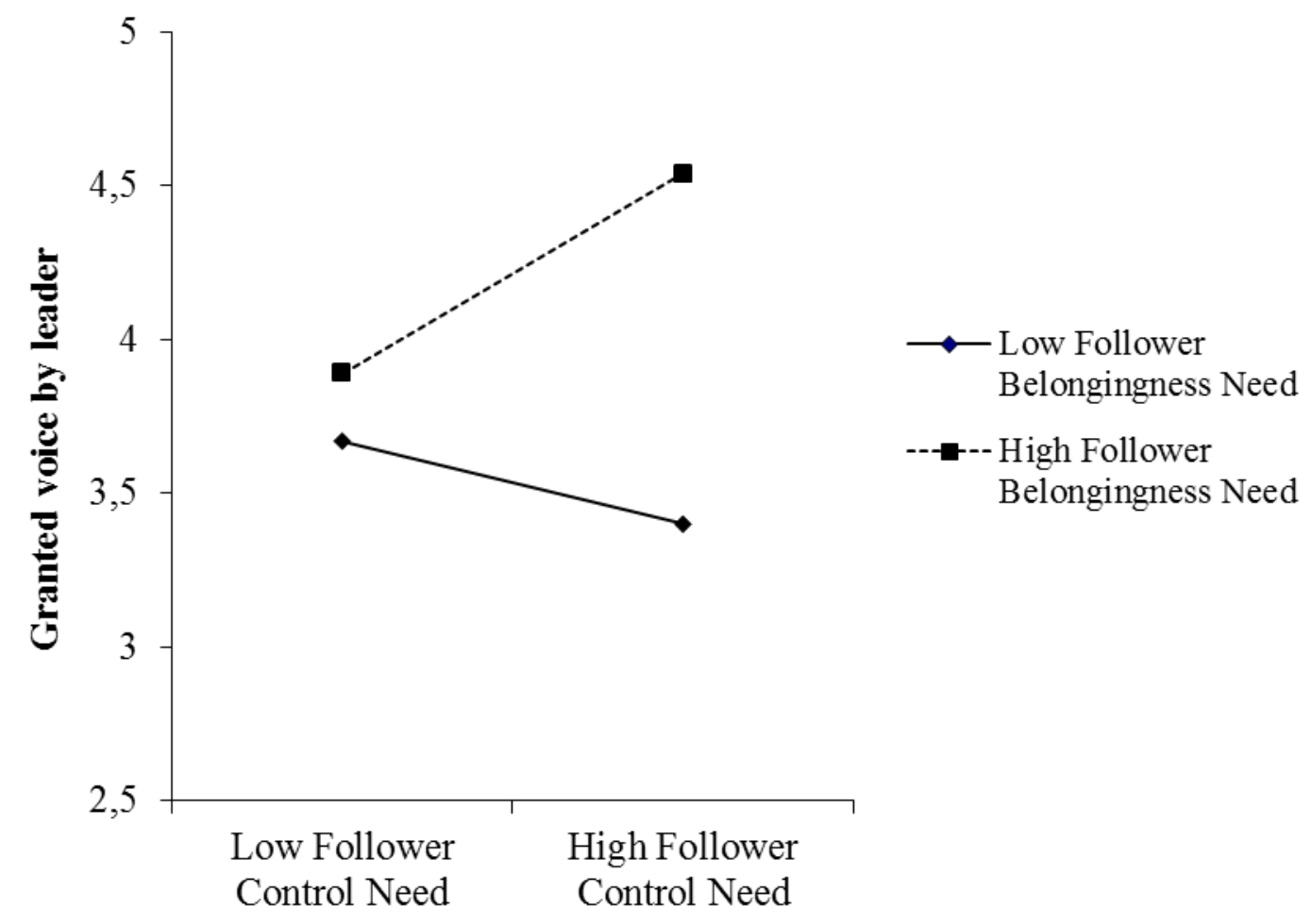

